\title{
EL SUJETO AUDIOVISUAL CONTEMPORÁNEO
}

THE CONTEMPORARY AUDIOVISUAL SUBJECT

FECHA DE RECIBO: JUNIO 6, 2012

FECHA DE ACEPTACIÓN: JUNIO 26, 2012

\section{AGUSTÍN ADOLFO GARCÍA SERVENTI}

\begin{abstract}
Candidato a Maestría en Diseño Comunicacional en la Universidad de Buenos Aires, Argentina.
\end{abstract} Docente catedrático del Programa de Diseño Gráfico en la Universidad Autónoma del Caribe.

\section{RESUMEN:}

La pregunta es por el sujeto, quién es ese sujeto que se somete a la experiencia estética cinematográfica y cómo responde a ella y cómo los medios interactivos resuelven este problema. Estos sujetos cinematográficos, que no han perdido esa característica de identificación con el advenimiento de la TV proponen un grado intensificado de identificación acaecido en la pantalla.

Pero ¿qué sucede en los medios interactivos o en el ciberespacio? Berenguer cita a Chris Crawford que define la comunicación interactiva como "un proceso cíclico, en el cual dos actores, alternativamente hablan, piensan y escuchan". "La estructura pasa a ser meta-estructura, como una síntesis de lecturas de varias imágenes superpuestas en las que se elige una participación activa del autor y del lector-espectador" (Berenger en La Ferla -compilador-2007) o interactor, como lo denomina Janett Murray (1999). Están surgiendo situaciones de expectación que la extienden a percepciones físicas, trasladan el cuerpo a acciones, proponiendo instancias "otras" para los sujetos que perciben el audiovisual. Esta nueva condición de hablar, pensar, escuchar y actuar.

PALABRAS CLAVE:

Sujeto audiovisual, espectador, interactor, interfaz, cine expandido, interacción.

\begin{abstract}
:
The question is the subject, who is this subject who undergoes aesthetic experience as film and responds to it as interactive media and solve this problem. These cinematic subjects, who have not lost that characteristic identification with the advent of TV, propose an enhanced degree of identification occurred in the screen.

But what happens in interactive media or in cyberspace? Berenguer quotes Chris Crawford defines interactive communication as "a cyclical process in which two actors alternately speak, think and listen." "The structure becomes meta-structure, as a synthesis of overlapping images readings in which active participation is chosen by the author and the readerviewer" (Berenger in La Ferla-compiler-2007) or interactor, as called by Janett Murray (1999). Expectation situations are emerging that extend to physical sensations, moving the body actions, proposing instances "other" for subjects receiving the audiovisual. This new condition to talk, think, listen and act.
\end{abstract}

\section{KEYWORDS:}

Audiovisual subject, spectator, interactor. interface, expanded cinema, interaction. 


\section{BREVE CONSIDERACIÓN DEL ESPECTADOR EN LA "FORMA CINEMA"}

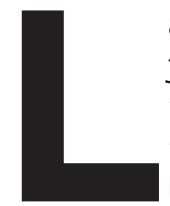

a pregunta es por el sujeto, quién es ese sujeto que se somete a la experiencia estética cinematográfica y como responde a ella; cómo los medios interactivos resuelven este problema es la intención en este apartado. Pero para ello veremos primero una aproximación a como lo hacía en el cine, en esta - como la llama André Parente - "forma cinema" 1.

El sujeto, aunque ausente de la escena, se encuentra incorporado a ella por el simple hecho de que la topografía del espacio está determinada por su posición: las proporciones relativas de los objetos varían según que esos objetos se aproximen al punto originario o se aparten de él .

El espectador de cine realiza una inmersión dentro de la historia, de la narración y de la imagen. Se inscribe como un observador otro, como un tercero en discordia entre la cámara, la escena filmada y él. Pero es el "observador" o "narrador" quien le trae el mundo hacia el espectador. El paradigma moderno todavía prevalece, es el universo el que viene al sujeto, es el todo que gobierna la razón el que se presenta al sujeto, al cógito. Pero en el cine esto no sucede desde el espectador, es él quien abandona su subjetividad para tomar la del otro, la de aquél que me muestra el mundo en la pantalla, dejo de ser yo por momentos y me muevo en un vaivén entre "esa" realidad (la de la pantalla) y "esta realidad" (la de la butaca).

Se encuentra en esta actitud un referente psicológico, un deseo "alienado de sí e identificado en otro, el sujeto es ese estado de ambigüedad se asume en las actitudes del niño, del actor y del espectador" ${ }^{3}$. Un sujeto deseante y pulsionante que quiere ser arrastrado por la fantasía de no ser lo quien es, para ser otro, en otro universo, donde todo puede ser posible y donde el fuera de campo permite que exista esa posibilidad, porque en el fuera de campo estoy yo, espectador, nuevamente cerrando el círculo de la fantasía y del deseo, circularidad que se repite y nunca se completa y perdura, en tanto dure el film. "Este deseo de ser engañado es central en el espectador"4.

Parente, A. "A Forma Cinema, variaçoes e rupturas", en K. Maciel, Transcinemas, San Pablo: Contracapa. 2009

Machado, Arlindo, El Sujeto en la pantalla. La aventura del espectador, de deseo a la acción, Buenos Aires, Gedisa ed. 2009

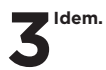

Comolli, Jean-Louis, “¿Fin del Fuera de Campo?”, en La Ferla, Jorge (comp.), Artes y Medios Audiovisuales, un estado de situación, Buenos Aires, Aurelia Rivera. 2007

\section{EL INTERACTOR, EL SUJETO YO Y EL SUJETO SE.}

Estos sujetos, no han perdido esa característica de identificación con el advenimiento de la TV, sino que se ha intensificado por las técnicas narrativas del medio: hablarle a los espectadores, es la característica fundamental de cualquier programa de TV conducido por alguna persona: “me dirijo a la teleaudiencia"..."mis seguidores comprenderán" (con la tradicional mirada apelativa a cámara de conductores y "artistas") propone un grado intensificado de identificación acaecido en "la pantalla"

Pero ¿qué sucede en los medios interactivos, o en el ciberespacio? Berenguer cita a Chris Crawford que define la comunicación interactiva como "un proceso cíclico, en el cual dos actores, alternativamente hablan, piensan y escuchan". Esta definición sirve para la interacción entre dos actores/personas, pero también para la interacción entre persona y ordenador, una vez aceptadas las correspondientes metáforas para este último. En términos técnicos, las actividades de hablar, pensar y escuchar se correspondes, respectivamente, con el input, el proceso y el output que caracterizan todo sistema automático ${ }^{5}$.

En el cine, es el director y el montajista quienes enlazan los eventos autónomos de una obra para suturarla y conformar una línea narrativa de sucesos. La estructura está previamente definida; pero en los medios digitales, la unidad está dada por la estructura relacional de los enlaces, que puede ser recorrida de múltiples formas (dependiendo del nivel de interactividad que propongan) y de acuerdo a las intenciones que tenga el "espectador" a la hora de recorrer la experiencia propuesta, "la estructura pasa a ser metaestructura, como una síntesis de lecturas de varias imágenes superpuestas en las que se elige una participación activa del autor y del lector-espectador" o interactor, como lo denomina Janett Murray ${ }^{6}$

\section{HABLA, PIENSA, ESCUCHA: ACTÚA.}

En contrapartida a la expectación frente al dispositivo cinematográfico de sala y con la consolidación ineluctable de los medios electrónicos (desde la Televisión hasta la computadora personal y los "teléfonos inteligentes" y los espacios audiovisuales inmersivos) a la vida cotidiana, están surgiendo situaciones de expectación que la extienden a percepciones físicas, trasladan el cuerpo a acciones, pro-

Berenguer, Xavier. "Una década de interactivos" . En La Ferla, Jorge (compilador), , El Medio es el Diseño Audiovisual, Manizales, Editorial Universidad de Caldas. 2007. Pag. 459-463.

Murray, Janet H.,Hamlet en la Holocubierta, el futuro de la narrativa en el ciberespacio. Barcelona, Paidós. 1999 
poniendo instancias "otras" para los sujetos que perciben el audiovisual. Esta nueva condición de "hablar, pensar, escuchar" y "actuar".

La tendencia que proponen estas instancias de visualización comenzadas por el zapping, es el de la falta de construcción del relato o de la fragmentación del modelo narrativo de continuidad lógica del relato, heredados del teatro, la novela y la ópera, predecesores del cine narrativo. Asistimos a la emergencia y paulatina consolidación de un modelo más que temporal, objetual o espacio-temporal. Youngblood $^{7}$ lo define precisamente describiendo el ingreso del computador como máquina audiovisual: “El ordenador libera al hombre de la especialización y amplifica la inteligencia". Ya no solo es del orden de lo visual y sonoro donde se dirimirán las fantasías espectaculares.

Se trata de otro tipo de identificación con la pantalla. Para el cine y la moda, la identificación era con un sujeto otro, con la imagen corporal de otra persona, alejado "de mi cuerpo", que tenía cosas que yo no poseo y por eso deseo, pedían identificación con el actor o la modelo, con la figura de otra persona. Pero en los medios interactivos, las narrativas interactivas "nos piden que nos identifiquemos con la estructura mental de otra persona. Si el espectador cinematográfico, hombre o mujer codiciaba y trataba de emular el cuerpo de la estrella de cine o la modelo, al usuario de ordenador se le pide que siga la trayectoria mental del diseñador de los nuevos medios". ${ }^{8}$

Se produce a partir de la televisión y el video (y se continúa fuertemente con los medios digitales computacionales) una crisis de la figuración, no respondiendo ya a los parámetros de identificación del cine, "el sujeto se convierte en la razón misma del acto de la figuración: ya no se trata simplemente de una imagen, sino de una imagen vista, que es visualizada, a partir de un lugar originario de visualización, por parte de algo/alguien, que es una especie de sujeto-máquina ${ }^{9}$.

Si se vuelve un poco mas atrás y se retoma la concepción del sujeto que se identifica no con lo visto sino con el ojo de la cámara, el observador omnipresente, jugando un doble juego, el de identificarse con lo que se ve (por acción del deseo de lo que está ahí) y con "el que ve" que es la cámara, el ojo mecánico. Machado ${ }^{10}$ cita a Couchot y lo

\footnotetext{
7 Youngblood, Gene, Expanded Cinema, NewYork, 2001 http://www. vasulka.org/Kitchen/PDF_ExpandedCinema/ExpandedCinema.htm (01/07/2010)

8 Manovich, Lev, El lenguaje de los nuevos medios de comunicación: la imagen en la era digital, Buenos Aires, Paidós. 2006

Machado, Arlindo, op. cit.

10 Idem
}

llama "sujeto-camara". Ahora, en la imagen digital e interactiva, este ojo, esta identificación no sucede pasivamente y cambia en el significado de su relación con la imagen y la pantalla que la contiene. Manovich ${ }^{11}$ propone un nuevo 0 doble juego en relación de la "cámara" con el objeto capturado, "imaginarnos que, de hecho, la cámara no se mueve en absoluto, sino que permanece inmóvil coincidiendo con los ojos del espectador. Y que en cambio es el espacio virtual en su conjunto el que cambia de posición con cada plano. Por emplear el vocabulario contemporáneo de las imágenes por ordenador, podemos decir que ese espacio virtual se le rota, se le cambia la escala, y se le aplica zoom, siempre para dar al espectador el mejor punto de vista" ${ }^{12}$. Esto propicia a que el interactor de los medios, experimente la imagen no como un relato que se le es dado, donde el punto de vista es puesto por otro, sino que sea el centro de la experiencia, y el universo se mueva en función de su posición y su mirada, al tener el control, el interactor modifica el universo y el punto de vista de acuerdo a su deseo y hace que se modifique por acción de sus comandos: teclado, mouse, joistick, o todo su cuerpo, en el caso de instalaciones de sensado corporal.

De esta característica que posibilita el medio digital, surge un nuevo sujeto de los que ya no será un soñador, será un actor, o un actor que sueña mientras actúa o actúa en sueños ${ }^{13}$. El sujeto que sueña y actúa, no sueña, porque actúa, pero inmerso en una realidad virtual puede también dejarse llevar por los avatares de la acción que proponen las nuevas formas narrativas como el videojuego. Este sujeto 0 instancia autónoma del receptor es llamada "agencia". El sujeto espectador ahora es gerenciado y autónomo y controla los parámetros que constituyen la narración tanto como las acciones y reacciones frente a los impulsos de él(los) otro(s) sujeto(s) interactuante(s) (otros humanos o máquinas).

La experiencia en los medios interactivos, propone otra experiencia de la subjetividad, ésta ya no proviene del deseo ni de la voluntad del sujeto, sino del automatismo y la programación del dispositivo técnico. El diseñador ya no solo se encarga de la visualidad y la construcción y producción de imágenes en movimiento y sonidos, sino de todo un campo de ejecuciones y programaciones en el ámbito digital orientados a provocar reacciones e interacciones con el 0 los interactores que pudieran intervenir en la obra. Machado

\footnotetext{
11 Manovich, Lev, op. cit. $12^{\text {item }}$

13 Comolli, Jean-Louis, “¿Fin del Fuera de Campo?”, en La Ferla, Jorge (comp.), Artes y Medios Audiovisuales, un estado de situación, Buenos Aires, Aurelia Rivera. 2007.
} 
(citando a Edmond Couchot) ${ }^{14}$ lo ejemplifica en una posible clasificación de este nuevo sujeto que ya no es un sujeto Yo, portante de subjetividad, sino un sujeto SE (pronombre indefinido que determinaría la indeterminación de ese sujeto que ya no es un humano sino unos procesos maquínicos).

Con la evolución de las tecnologías de producción simbólica, hay un momento en que los procedimientos de construcción ganan autonomía: pueden funcionar sin la intervención (o con un mínimo de intervención) de un operador...en el fondo de todos los enunciados técnicamente, ya no estaría actuando "o por lo menos no exclusivamente", un inconsciente psíquico, imponderable, sino una especie de inconsciente maquinal, multiforme pero delimitado y programado ${ }^{15}$

En esta nueva subjetividad, "el ojo visualizador está en todos los lugares y al mismo tiempo en ninguno. En vez de ser un observador distante, como en el renacimiento, hoy ese nuevo sujeto está implicado en el mundo virtual en el que se halla inmerso" ${ }^{16}$, es el individuo, hoy, quien se desdobla para hacerse dividuo como menciona Gilles Deleuze ${ }^{17}$, el sujeto nuevo, se complementa con el precedente, emerge desde el fondo obscuro de la programación numérica y de los cables del hardware y se multiplica en los avatares y objetos digitales que navegan por el ciberespacio. Este posible desdoblamiento, esta nueva experiencia de subjetividad en el ciberespacio, no deriva de una "voluntad, de un deseo de una iniciativa, de la omisión de un sujeto constituido (aunque ausente) sino de automatismos del dispositivo técnico" ${ }^{18}$.

El sujeto, la subjetividad proclamada por los las teorías psicologistas del cine, cambió con el cine, se expandió con él y con su espectáculo, tomó de las tecnologías, formas de ser y estar en el medio. Es la consolidación del sujeto SE, un sujeto que proviene de la mente (y la programación) de una persona, pero que toma vida propia, determinada por su función como objeto dentro del programa, actúa independientemente, como un algoritmo matemático. SE por (sujet$0 \mathrm{~N}$, en francés ${ }^{19}$ ) que implica una indeterminación como el pronombre indefinido. El pronombre identifica a las cosas

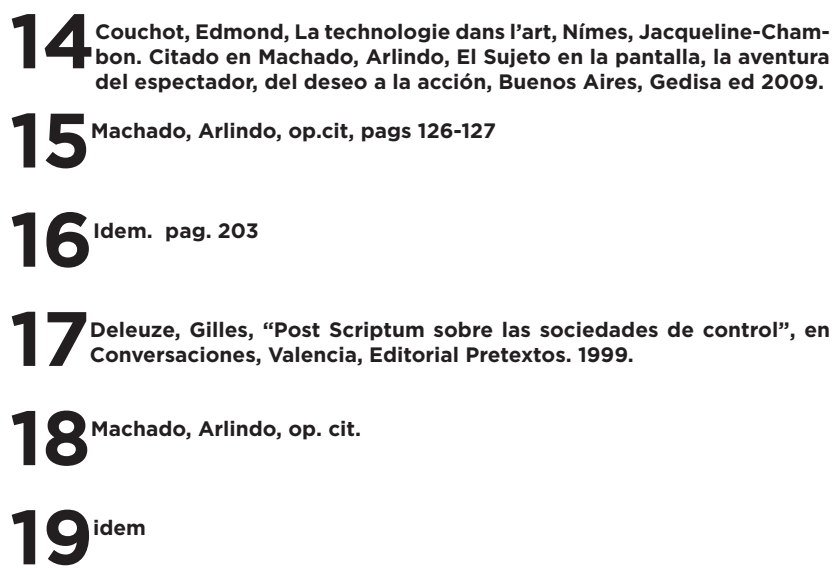

indefinidas de las cuales no se tiene referencia concreta, por ejemplo "se sabe".

Resumiendo la teoría de Couchot, Machado dice que primero surgieron tecnologías que suplantaban la percepción de la mirada, como las cuadrículas de Durero o la tavoletta de Bruneleschi, transfiriendo parte de la mirada al dispositivo tecnológico. Luego, en otro salto epocal, la cámara fotográfica automatiza la función de la mano, que ya no pinta la imagen, emergiendo lo que Couchot llama (como lo hicimos anteriormente) el sujeto-cámara, que depende de la máquina para realizar las operaciones de Ver y Representar. Es un YO que está ausente, un observador mecánico ${ }^{20}$. Esta indefinición no implica que este sujeto SE pierda las cualidades de tal y se convierta en objeto, pero es despersonalizado y anónimo. En lugar de borrarse y perder su función - Apunta Machado - el sujeto se convierte en la razón misma del acto de figuración: se trata de una imagen vista que es visualizada partir de un lugar originario de visualización por algo/alguien que es una especie de sujeto máquina. En relación con la imagen cinematográfica, Machado asegura que Couchot introduce un desvío en la concepción de desdoblamiento psíquico del espectador, ya que parte de ese desdoblamiento está, de alguna manera controlado o sugerido por un observador maquínico, por una especie de "inconsciente maquínico", que en el caso del ordenador, puede funcionar como un inconsciente psíquico, con lapsus, fallos, errores de programación, virus o conflictos internos de compatibilidades de la maquina.

Esta concepción del sujeto SE puede graficarse con la cámara automática, que saca fotos sin necesidad de que una persona lo haga, o las cámaras que ayudan a un robot (o son sus ojos) para seleccionar y ordenar objetos en un proceso de producción y selección industrial como una fábrica de tornillos o de automóviles, "del mismo modo que en el universo de los medios digitales un usuario también puede interactuar con un artefacto y obtener de él un determinado resultado, sin tener la mas mínima idea de cómo es que los textos, las imágenes y los sonidos se producen en las entrañas del ordenador ni de cómo responden a sus demandas." ${ }^{21}$

De esta forma, surgen dos sujetos bien determinados pero que se mezclan permanentemente en sus "funciones" cuando interactúan con la máquina y los medios digitales, el Sujeto Yo o interactor que machado llama "demiurgo"22 porque al sumergirse en la experiencia virtual hace que se

2 Alessandria, Jorge, “Imagen y metaimagen”, Buenos Aires, Eudeba. 1996.

21 Machado, Arlindo op. cit., pag. 128

2 Machado, Arlindo op. cit. Refiere a demiurgo como controlador del universo, en el juego Age of Empire, el interactor controla los acontecimientos del universo virtual, como si fuera la figura de un Dios. 
desencadenen los sucesos en la diégesis de la pantalla y otro sujeto, el SE, un programa de generación automática de situaciones narrativas, que interactúa con el primero. El programa no toma decisiones por sí mismo (en la interacción) sino que responde a las demandas del interactor de acuerdo a su programación y lenguaje intrínseco. El programa entonces se establece como una especie de metanarrador que posibilita que surjan las operaciones e interacciones con el programa y también puede establecerse como un personaje, cuando se enfrenta a un interactor en los videojuegos. Un claro y popular ejemplo de este comportamiento es el juego The Sims, donde el interactor gobierna las acciones del personaje (que es su representación maquínica) pero este reacciona ante posibles "malos usos" y hasta puede morir por causa de ellos, también funciona como una "metanovela" del "american way of life". El interactor puede definir tanto sexo, edad, peso, aspecto físico del "personaje" como también aspectos más complejos como "amigabilidad" (capacidad de relacionarse con otros Sims) que determinan la "personalidad" del personaje.

\section{El interactor y la interfaz, interrupción, simultaneidad y selección.}

La comprensión del mundo es en realidad un problema de interfaz.

Peter Weibel

Este problema de la comprensión del mundo es central para comprender todas las prácticas del diseño y como se ven modificadas por la máquina. A la hora de pensar en diseño audiovisual interactivo, abordar el concepto de interfaz relacionada con el interactor es esencial para comprender el rol que el diseño audiovisual está tomado en la cultura audiovisual. Las interfaces gráficas de usuario (GUI sus siglas en ingles) son el nexo entre el sujeto YO y el Sujeto SE y a su vez este con la máquina propiamente dicha y a través de la máquina con las redes.

"Por primera vez en la historia, la imagen es un sistema dinámico de secuencias de acontecimientos de variabilidad acústica y visual y de información virtual que solo depende del observador. $Y$ con ello se da origen a una nueva visión que integra al observador con el medio técnico"23.

La interfaz por lo tanto, no debe considerarse desde el punto de vista del dispositivo que relaciona al interactor con la máquina sino desde sus tensiones entre lo individual y lo social. Que modifican comportamientos y acercan a las personas a interconectarse entre sí. En esta concepción $25 \begin{aligned} & \text { Lodoño, Luis Felipe, EI lenguaje visual digital: la estructura del } \\ & \text { lenguaje visual dinámico en los sistemas interactivos. http://www2. }\end{aligned}$ udec.cl/ai/feli.htm (11/07/2009) no deben considerarse solo los polos abstractos representados por la interfaz y la máquina, sino que intervienen también la memoria, la imaginación, los conocimientos y sentimientos del interactor que se relaciona directamente con el las bases de datos, las conexiones con esta y otras bases de datos en la cadena significante(¿piercieana?) de este nuevo lenguaje informático.

Estas capacidades del interactor se materializan en el "propio movimiento estético de la interfaz, en su forma, estableciendo constantemente nuevas plataformas que procuran posibilidades también nuevas de interconexión"24. La interfaz - dice Doménech - puede ser materializada como el movimiento mental, materializado en la pantalla del ordenador, otorgándole al interactor, no solo las facultades de decidir sobre los objetos digitales, sino de impregnarles su condición de sujeto, su capacidad de resolver problemas, de interactuar con otras personas, en definitiva el modelo mental que obliga readaptar los procesos de diseño permanentemente.

$Y$ a diferencia del cine, donde la mayor parte de los usuarios son capaces de entender el lenguaje cinematográfico pero no de hablarlo, (es decir de hacer películas), todos los usuarios del ordenador saben hablar el lenguaje de la interfaz, son usuarios activos de la interfaz, y la emplean para realizar muchas taereas, desde enviar correo electrónico, a organizar archivos, ejecutar aplicaciones varias, etc ${ }^{25}$.

Aunque la primera acepción es hoy ya pasada un poco de moda, debido a la proliferación de aparatos videográficos, cada vez más interactores de los nuevos medios están convirtiéndose en productores cinematográficos. Si tomamos como estrictamente cinematográfico el cine hecho por grandes productoras de largometraje, entonces si, mucha gente no sabe hablar ese lenguaje, pero cada vez más se está manifestando su pericia en plataformas como youtube, vimeo, metacafé ${ }^{26}$, verdaderas bases de datos audiovisuales donde se puede comprobar la proliferación de cinematografía "hecha en casa" y donde los interactores generan sus propios canales de televisión virtual en meta-medios de comunicación. "El ordenador, el televisor, el teléfono, la radio o el vídeo, integrados en la tecnología digital, configuran una nueva individualidad, donde el espectador personaliza la imagen que consume y los contenidos de la información." Estos nuevos espectadores, ahora interactores, "ganan en presencia e identificación, e intervienen en la experiencia audiovisual y a la vez, la

Català Domènech, Josep M., "Problemas de la representación del espacio y el tiempo en la imagen", Portal de la Comunicación, Institut de la Comunicació, http://www.portalcomunicacion.com/ESP/pdf/ aab_lec/8.pdf, (01/09/2010)

25 Manovich, Lev, op. cit.

26 www.youtube.com, www.vimeo.com, www.metacafé.com, etc. 
comparten con otros"27 conformando redes semánticas interconectadas con todas las experiencias estéticas audiovisuales posibles dentro de la inmensa nube de datos donde los medios interactivos están insertos.

\section{REFERENCIAS BIBLIOGRÁFICAS}

Alessandria, Jorge, Imagen y metaimagen, Buenos Aires, Eudeba. 1996

La Ferla, Jorge, Cine (y) Digital, Buenos Aires, Manantial. 2009.

(compilador), El Medio es el Diseño Audiovisual, Manizales, Editorial Universidad de Caldas. 2007. --------------- Artes y Medios Audiovisuales, un estado de situación, Buenos Aires, Aurelia Rivera. 2007.

Machado, Arlindo, El Sujeto en la pantalla, la aventura del espectador, del deseo a la acción, Buenos Aires, Gedisa ed. 2009.

Manovich, Lev, El lenguaje de los nuevos medios de comunicación: la imagen en la era digital, Buenos Aires, Paidós. 2006.

Murray, Janet H., Hamlet en la Holocubierta, el futuro de la narrativa en el ciberespacio. Barcelona, Paidós. 1999.

Youngblood, Gene, Expanded Cinema, NewYork, http:// www.vasulka.org/Kitchen/PDF_ExpandedCinema/ExpandedCinema.html (01/07/2010)

\section{ARTÍCULOS}

Berenger, Xabier, "Una década de interactivos", en LaFerla, Jorge (comp.), El Medio es el Diseño Audiovisual, Manizales, Editorial Universidad de Caldas. 2007.

Català Domènech, Josep M., "Problemas de la representación del espacio y el tiempo en la imagen", Portal de la Comunicación, Institut de la Comunicació, http:// www.portalcomunicacion.com/ESP/pdf/aab_lec/8.pdf, (01/09/2010)

Comolli, Jean-Louis , ¿Fin del Fuera de Campo?”, en La Ferla, Jorge (comp.), , Artes y Medios Audiovisuales, un estado de situación, Buenos Aires, Aurelia Rivera. 2007. Deleuze, Gilles, "Post Scriptum sobre las sociedades de control", en Deleuze, Gilles, Conversaciones, Valencia, Editorial Pretextos. 1999.

Lodoño, Luis Felipe, El lenguaje visual digital: la estructura del lenguaje visual dinámico en los sistemas interactivos. http://www2.udec.cl/ai/feli.htm (11/07/2009)

Parente, A., "A Forma Cinema, variaçoes e rupturas". En K. Maciel, Transcinemas, San Pablo, Contracapa. 2009.
Youngblood, Gene, "Cinema and the Code", Leonardo. Supplemental Issue, Vol. 2 tomado de: www.vasulka.org/ archive/4-20b/Leonardo(9002).pdf 